ing velocity of rotation; yet there is a "missing link" which cannot readily be supplied. Friction against a surrounding medium, combing out, as it has been expressed, the vapours in a longitudinal direction, can hardly be admitted on mechanical grounds; and there is difficulty in conceiving the arrangement of the restoration of equilibrium in currents which set in one direction over the whole visible globe, if they originate by ascending from warmer depths, and lagging behind in a higher and more swiftly rotating region. We may remark, in passing, that only a trifling elevation of the luminous above the grey region, with a corresponding slight difference in velocity of rotation, is compatible with the undeviating contour of the limb as far as our telescopes may show it ; though, of course, given an unlimited duration of time, the slightest preponderance would be ultimately adequate to such an effect. Possibly the best explanation may lie in some modification of electrical or magnetic polarity. At any rate the influence, though predominant, is not irresistible, since it neither precludes the formation of belts of a certain amount of obliquity, nor mixes up in confusion, though it seems to elongate, those very remarkable insulated luminous masses which occasionally encompass the gigantic equator in a comparatively equable series with a string of great oval beads, sometimes so curiously and uniformly shaded as to convey an almost irresistible impression of high relief. This strange phenomenon, not confined, as Dawes has found, solely to the equator, seems wholly beyond our conjectures. Nor can we satisfactorily explain those large spots, much darker than the belts, as though the atmosphere were there more perfectly transparent, which have occasionally shown such remarkable persistency as to indicate some relation to definite regions on the surface beneath them; at other times have disappeared with startling rapidity; and usually have been so far from absolute immobility that every attempt to determine the rotation by their means has ended in mere approximation. The occasional detection, too, of many minute white specks, like passing satellites, in various parts of the disk, has added nothing to our knowledge beyond the fact of their presence. The abnormal flattenings of the limb which have sometimes been noticed on the approach of a satellite, or even without it, seem to be of an illusory nature. And yet nothing should pass without attention.

Few things in this wonderful planet are more striking than the singular and beautiful colouring which occasionally adorns the disk. For a considerable season nothing beyond some feeble tinge may be made out, especially in the equatorial zone; then again we shall find purple, brown, greenish yellow, orange, and rosy tints marking out the surface with delicate but unmistakable variety. The darker the grey of the belts, the more apt it is to show a slaty purple hue; the polar regions sometimes, as at present, differ slightly in tint, so that temperature does not seem to be connected with it. The rosy spot of the present season south of the equatorial zone has naturally attracted much attention, and wili of course be carefully watched. But as yet the origin of such varieties of colour sets conjecture at defiance. To depict these many changes both of form and bue will always be an interesting occupation, though it is never likely to have any more definite result than to deeren our sense of the wonders of creation, and our reverence for its First Great Cause.

One caution may be permitted here. It would be very desirable for those who attempt to delineate this magnificent planet that they should make themselves familiar with the persfective of a globe. The telescopic image has so precisely the aspect of a flat disk that it requires some mental effort to realise the fact that we are gazing on a great ball; and unless this is carefully borne in mind our drawings will and must be unsatisfactory. Especially it is perhaps seldom imagined how very little we know of the Polar regions, from an obliqueness of presentation amounting to virtual and unbroken concealment. From the analogy of Saturn we may infer that the poles of Jupiter present no remarkable feature; but it must ever remain a mere conjecture to all future generations.

It scarcely needs to be mentioned that no circular representation of the disk can ever give a resemblance tolerable to an experienced eye. An elliptical outline, apparent even with a power of 30 or 40 , is too striking a characteristic not to affect materially the faithfulness of the picture.

Something remains to be said as to the beautiful retinue which attends on this leader of the planetary system and whose perpetual change of configuration is ever a source of fresh interest. In some respects they are subjects only for the finest telescopes, in others a very slight optical power can deal with them. The true dimensions of those minute disks are, perhaps, as fairly known as can be expected from measures of such difficulty; but the subject of their numerous changes of brilliancy, though frequently treated, cannot be said to be fairly exhausted. That such changes exist, and to an extent easily recngnised in very moderate telescopes, is undeniable; and were they constant for the same orbital positions, they would find ready explanation in the very natural supposition that they rotate like our own satellite, each on his own axis, in the same time that they complete their monthly period. But this idea, though it approved itself to Herschel I. and Schröter, is found inconsistent with observation, which shows the changes to be too irregular in their returns ; and we can only infer, what, indeed, has been actually shown by good instruments, both in front of and outside of the face of the primary, the variable darkening of portions of their disks, a result which, interpret it how we may, by atmospheric change, or unsymmetric rotation, or a combination of both (and no other supposition seems to occur), removes those little bodies still further from our analogies. There is no more resemblance between these satellites and our moon than there is between the primaries on which they respectively attend.

We must postpone our remarks on Saturn and Mars to a future opportunity,

T. W. WEBB

\section{NORDENSKJÖLD'S ARCTIC VOYAGES}

$\mathrm{I} \mathrm{T}$ is fifteen months, our readers will remember, since Prof. Nordenskjöld left Hammerfest in the Vega. to prove that, if taken at the proper time, the NorthEast Passage is perfectly practicable. And the result has proved that he was right to within a day or two. Nearly a year ago he had practically accomplished the passage, and was only overtaken by the ice just as he was about to emerge into the Pacific. We know already that during their year's enforced imprisonment in the ice to the east of Serdze Kamen, Prof. Nordenskjöld and his accomplished and well-selected staff have made the best possible use of their time. We have already, on several occasions, briefly referred to some of the valuable results obtained in various departments of science, and the full narrative of the expedition. will be looked for with impatience. We hope that it will be given to the world with the least possible delay after the leader's return to his home in Stockholm. Meantime we are concerned, not with this culmination of a long; series of expeditions in the Arctic waters to the north of the Old Continent, but with the exploring work of its leader during the previous twenty years. Mr. Leslie has done good service in wading through the voluminous literature of Nordenskjöld's various expeditions, and' culling from it the material wherewith to compile a

I "The Arctic Voyages 'of Adolf Erik Nordenskjöld, 1858-1879." With Illustrations and Maps. (London: Macmillan and C.., 1879.) 
volume of genuine interest and of much scientific value, well provided with maps, and rendered attractive by numerous illustrations.

Mr. Leslie gives a preliminary account of the life of his hero, mostly in the latter's own words, and this is perhaps the most interesting part of the volume. Many of our readers do not need to be told that Prof. Nordenskjöld is a remarkable man, altogether apart from the long series of explorations in which he has done so much for a scientific knowledge of the Arctic regions. Nordenskjöld is a native of Finland, having been born in I 832, the descendant of an old family of good position. His father was chief of the Mining Department of Finland, and a well-known naturalist. Other members of this family were eminent in various departments of literature and science, and the grandfather, Col. Nordenskjöld, built a peculiar residence at Furgord, where stores of natural history have been collected. Here young Nordenskjöld was brought up, and while yet a boy was an industrious collector of minerals and insects, and was permitted to accompany his father on his tours, acquiring thus early the keen eye of the mineralogist. After attending the Gymnasium of Bergo for some time-

"Nordenskjöld entered the University of Helsingfors in 1849 , devoting himself chiefly to the study of chemistry, natural history, mathematics, physics, and above all, of mineralogy and geology. 'Already before I became a student,' he writes, 'I had been allowed to accompany my father in mineralogical excursions, and had acquired from him skill in recognising and collecting minerals and in the use of the blowpipe, which he, being a pupil of Gahn and Berzelius, handled with a masterly skill unknown to most of the chemists of the present day. I now undertook the charge of the rich mineral collection at Frugord, and besides, during the vacations, made excursions to Pitkeranta, Tammela, Pargas, and others of Finland's interesting mineral localities. By practice I thus acquired a keen and certain eye for recognising minerals, which has been of great service to me in the path of life I afterwards followed.'

"After passing his candidate examination in 1853, Nordenskjöld accompanied his father on a mineralogical tour to Ural, devoting most of his attention to Demidoff's iron and copper mines at Tajilsk. Here he planned an extensive journey through Siberia, but the breaking out of the Crimean war put a stop to it.

"'After my return,' says Nordenskjöld, 'I continued to prosecute my chemical and mineralogical studies with zeal, and wrote as my dissertation for the degree of Licentiate a paper "On the Crystalline Forms of Graphite and Chondrodite," which was discussed under the presidency of Prof. Arppe on February 28, 1855. The following summer I was employed on a work of somewhat greater extent-" A Description of the Minerals found in Finland," which was published the same autumn. Various short papers in mineralogy and molecular chemistry were printed in "Acta Societatis scientiarum Fennix ;" I also published, along with Dr. E. Nylander, "The Mollusca of Finland" (Helsingfors, i 856), as an answer to a prize question proposed by one of the faculty. In the interval I had been appointed Curator of the Mathematicophysical Faculty, and had obtained a post at the Mining Office as mining engineer extraordinary, with inconsiderable pay, and an express understanding that no service would be required from me in return. A salary was also attached to my curatorship.'"

Nordenskjöld did not, however, long enjoy these, his first paid appointments. Finland has never taken kindly to her severance from Sweden and her attachment as a province to Russia. Nordenskjöld naturally had a great love for Sweden, and on one or two occasions gave expression to his feelings in speeches at social gatherings. These expressions were certainly not significant of anything like disloyalty to Russia, but the shortsighted governor of the time magnified them into something like high treason. The result was that Nordenskjöld left Finland in 1857 and took up his residence in Stockholm; since then he has been to all intents and purposes a subject of the Swedish Government, and has risen in his adopted country to high honours. Shortly after his arrival he was appointed assistant to the celebrated mineralogist, Mosander, and in December, I858, on the death of the latter, succeeded him as Professor and Intendant of the Mineralogical Department at the Riks-Museum of Copenhagen. Before this he had travelled and studied in various parts of Europe, especially in Berlin, had visited the Ural Mountains, and explored part of Finland. Since then he has more thoroughly explored Finland and visited many parts of the Scandinavian Peninsula, as a mineralogist. We need not remind our readers of the great amount of work done by Nordenskjöld, during the past twenty years in mineralogical investigation; his researches in this department have entitled him to take a high rank in his own department.

As a scientific explorer, Nordenskjöld is mainly known in connection with the work he has done in the five expeditions to Spitzbergen, of which he has been a member. These expeditions, it should be remembered, were not undertaken for the mere purpose of creating a sensation by the foolhardy feat of attempting to reach the pole at all hazards. Geographical discovery certainly formed a part of the programme of all the expeditions in which Nordenskjöld has been engaged, and on these occasions it was attempted to push as far north as was consistent with safety. In the expedition of $\mathrm{I} 868$, for example, the Sofia succeeded in sailing to $81^{\circ} 42^{\prime} \mathrm{N}$. in $17^{\circ} 30^{\prime} \mathrm{E}$. long., I $2^{\prime}$ beyond Scoresby's farthest; and in the spring of 1873 an attempt was made in man-drawn sledges (thirty-nine of the forty reindeer had bolted, and were never seen again) to push beyond the Seven Islands, but the condition of the ice was such that Nordenskjöld prudently abstained from risking his men's lives. The vessels in which the various expeditions have sailed have been of very small tonnage, in one case only $26 \frac{1}{4}$, but this Nordenskjöld considered an advantage in pushing through the drift-ice. The expenses of the expedition have always been moderate, partly defrayed by Government, but mostly by private subscription; as our readers know, one of the most liberal supporters of Nor lenskjöld's exploring undertakings has been Mr. Oscar Dickson, the wealthy Gothenburg merchant, to whom Mr. Leslie's volume is appropriately dedicated. The results obtained in these modest and inexpensive expeditions contrast strongly with those of the expensive and elaborately equipped expedition in the Alert and Discovery. On all these expeditions Nordenskjöld has been accompanied by a competent scientific staff, and the results obtained, both in the natural history and the physics of the Arctic region, have been of the first importance. By means of these and other researches the Riks-Museum of Stockholm has now, probably, the richest collection in mineralogy in the world.

On the first two expeditions to Spitzbergen, in which Nordenskjöld was engaged, I858 and 1861 , he acted as geologist under the leader Otto Torrell, the head of the Swedish Geological Survey. On the former of these sereral parts of the west coast were visited and explored. At Bell Sound, on the south-west of the main island "dredging was undertaken with abundant success, birds and mammalia were shot and prepared, a tertiary formation containing fossil plants discovered, and botanical collections made, particularly of mosses and lichens. "On July 6 they left this anchorage to sail northwards, but calms and head-winds compelled them to seek the north harbour in the same fjord. There Nordenskjöld discovered thick vertical strata of limestone and siliceous slates rich in fossils of the genera Productus and Spirifer, and which therefore appeared to belong to the carboni- 
ferous formation, and found these strata overlain by other nearly horizontal beds belonging to the same tertiary formations with impressions of leaves as he bad observed at Middle Hook.'

The expedition of $186 \mathrm{r}$ consisted of two tiny vessels. They managed to sail right round the west and north coast to the entrance of Hinlopen Strait, which divides the main island from North-east Land, anchoring in Treurenber: Bay, the starting-point of Parry's famous sledge expedition of 1827 .

"The Swedes paid a visit to Hecla Cove, Parry's harbour, protected from the north by Cape Croziex with its hill of quartzite. It was on this point that Parry and his lieutenant, Crozier, carried on their magnetic and astronomical observations, and on this height they erected a flagstaff with a copper plate bearing an inscription to preserve the memory of their visit. Here was found a flagstaff, which, however, was only the highest portion of Parry's flagstaff, and the copper plate was cut away so that only a few small pieces remained under the heads of the nails with which it had been fastened. Hecla Mount, about I,720 feet high, was ascended, and from its top an extensive view was obtained of North-east: Land, which along the coast is very flat with rounded bills of inconsiderable height, and in the interior is covered with a continuous snow-plain of about the same or somewbat greater height above the sea than the top of Hecla Mount, and to the south of Niew Vriesland, the interior of which is also occupied by a similar unbroken snow-plateatr. In the neighbourbood large masses of hyperite were found; and to the iron which the eruptive rock contains the Swedes attributed certain irregularities which appeared in the magnetic observations. Interesting as was the discovery of this rock on the other

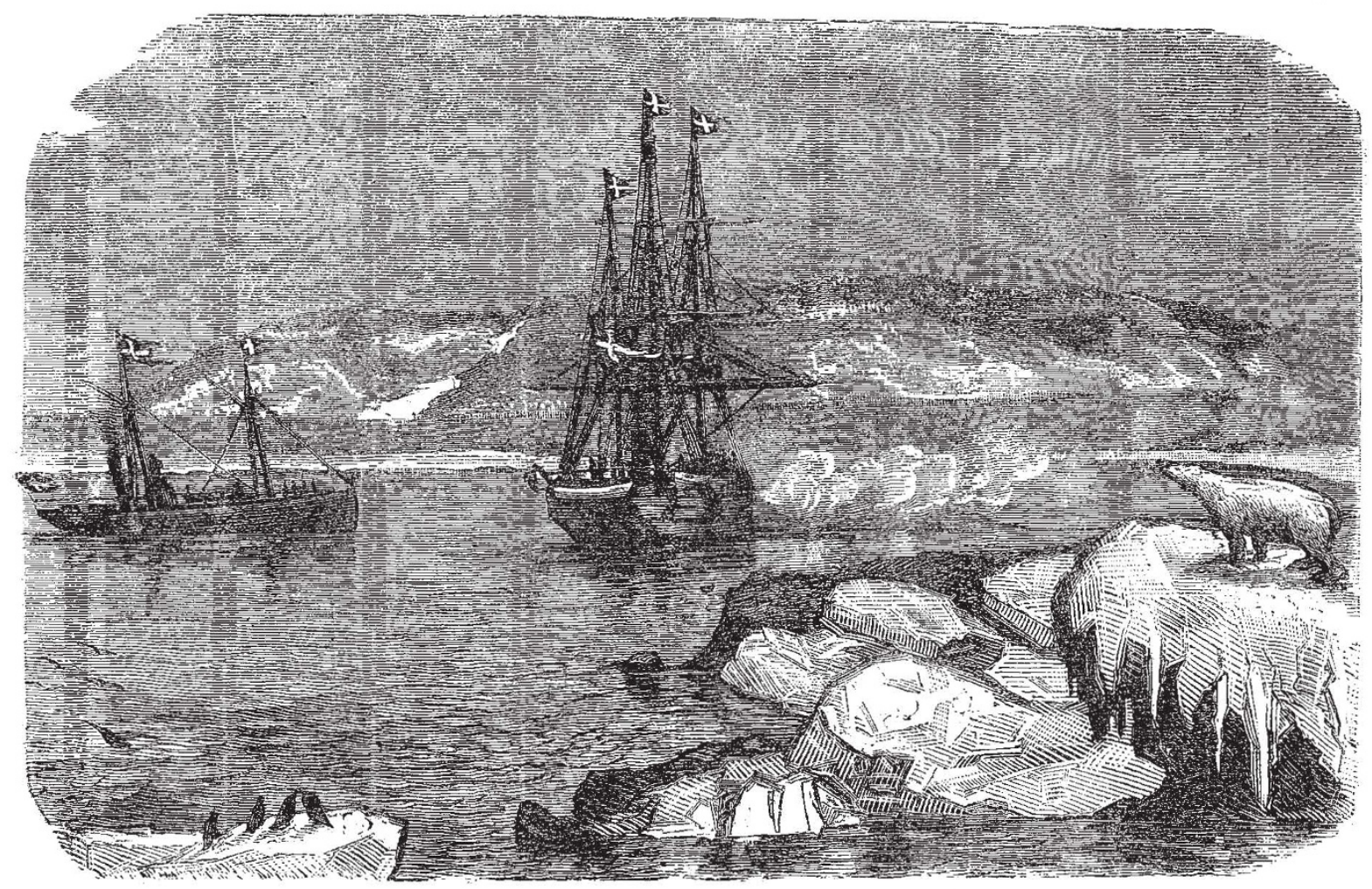

Cape Chelyuskin, the Northernmost Point of the Old Worid.

side of the bay to the geologists, it was not so to the physicists, who found that all their magnetic observations were affected by its presence.'

During the weeks that elapsed from the imprisonment of the vessels in Treurenberg Bay till their release, the zoologists carried on dredgings, the other members of the expedition were employed in copying charts, with a view to future excursions, and in calculating observations; on board the Asolus meteorological observations were taken hourly; measurements were also made of the tides.

"At length the ice broke up, and on July 2 the ships got out to sea accompanied by the Faen Mayen, a fishing vessel that had been imprisoned along with them.

"June is the spring month of Spitzbergen. The sun rose higher and higher above the horizon, and his rays were by no means powerless. The snow first became soft and water-drenched, and disappeared in spots from the ground. On June II Cochlearia fenestrata, and the polar willows began to open their buds; on June 22 the first expanded flowers of Saxifraga oppositifolia were: gathered, a sign that the midsummer sun had at length won a victory over the northern winter, and on the 26 th there were in flower Draba alpina, Cochlearia, Cardamine bellidifolia, and Saxifraga cermua, and here and there Oxyria, and the willow, and in the beginning of July Ccrastinm alpinum. Small Poduri hopped about in a lively way among the snow. By June 7 there were seen on Hecla Mount, more than 1,500 feet above the sea, a number of gnats, and on the 2Ist there were captured near Folus's cross Diptera, which, however, were unable to raise their wings to a higher flight than a foot or two from the ground. Small spiders and a kind of worm, like our dew-worm, living in the already thawed ground, were found here and there."

After the ice broke up Torell and Nordenskjöld undertook a boat journey down Hinlopen Strait, during which a variety of important data were obtained and collections made. At several places they found immense glaciers, 
one about seven miles long, and standing out into the sea with its perpendicular walls. South of Wahlenberg's with ; these were the first fossils found in North Spitzbergen. After collecting a large quantity of fossils at Angelin's Mount, on the south-west of North-East Land, the party rowed along the shore to another mountain, 2,000 feet high, which strongly resembled it. 'This they named Lovén's Mount. Its upper part consists of hyperite, and with its flat, steep, and black sides strongly resembles a roof. Underlying the byperite are horizontal lime-and sand-stone strata with nearly perpendicular faces towards the sound giving the whole mountain the appearance of a regular colossal building. Another rich collection of fossils was made here. The party then proceeded down the strait, but after two hours' rowing were met by fast ice which obliged them to turn. They then rowed along the west side of the sound, taking an hour to pass a broad glacier. After it they came to another which lay like a stratum of rock on a perpendicular cliff of hyperite, and accordingly tumbled with its ice over the rocks into the sea. The hyperite was found to be beautifully polished and marked, and here, as at several other places, were found many signs that the ice in former times had occupied a larger area on Spitzbergen. Between Dym Point and Cape Fanshawe the Swedes passed the greatest auk-fell they had hitherto seen. Here also was found, rising from the sea to a height of 1,000 feet, a perpendicular wall of hyperite, cverywhere split vertically into basalt-

like, upright, four- or eight-sided columns, standing | evidence that the Gulf Stream reaches this high latitude. free or only connected with the main rock by a small After the return from Hinlopen Strait, Torell and corner, and sometimes crowned capitalwise by a stratum of greyish-white limestone. After passing Cape Fanshawe the party next entered Lomme Bay, on the west side of which they found the largest glacier they had yet seen on Spitzbergen. It is about ten miles wide, and projects into the sound with a curved front. The stratification of the ice is horizontal. At Shoal Point, at the entrance to Hinlopen Strait, the beach was everywhere covered with an enormous mass of drift-wood among which are found pieces of pumice-stone, birch-bark, cork, poles, and floats from the Lofodden fisheries, with other things which had been carried hither by currents from the south. The drift-wood formed a broad line along the beach. Farther up was another line, where the water now scarcely comes even during spring tides, probably elevated by a raising of the land. In this line the drift-wood was far older and undergoing decomposition. While Torell was examining all this, he found among other things a well-preserved bean of the West Indian plant Entada gigalobium. This bean, I Nordenskjöld explored a part of the north coast of North which is upwards of an inch and a half across, floats East Land. Near Waygatz Islands, on the south of 
Hinlopen Strait, where one of the vessels lay for some time, the divergence between the marine fauna of East and West Spitzbergen was very striking. Here were found animals belonging exclusively to the faura of Greenland, seen exceedingly seldom or never on the west coast. As an example of the flora to be found in Spitzbergen and of the thoroughness with which the expedition did its work, we quote the following passage from $\mathrm{Mr}$. Leslie's volume :-

"After various excursions had been made the Magdalena sailed from the Norways on the $25 \mathrm{th}$, and after passing Kobbe Bay and South Gat, the sound between Danes' Island and the mainland, anchored in Magdalena Bay. Here, at a height of 2,300 feet above the sea, the following plants were found growing, Cochlearia fenestrata, Cerastium alpinum, Luzula hyperborea, and several saxifrages; lower down, small soft tufts of the Arctic willow, Alsine biflora, and several grasses. Out of the gravel there rose nearly a foot high here and there the uncommon Saxifraga hieracifolia and Pedicularis hirsuta with its reddish head, alternating with yellow Ranunculi and bright red patches of the graceful Silene acaulis, of which, however, a flower here and there had begun to pale under the powerful rays of the sun, which had already caused several Draba and the here uncommon Arabis alpina to go to seed. High up on the fell grew the beautiful Erigeron uniflorus. By the side of the small streams that flowed from the top to the bottom of the mountain were mosses, Saxifraga rivularis, Stellaria eduardsi, and two species of Poa. It is remarkable that the vegetation diminishes quite inconsiderably with the height above the sea, so that almost all the plants that grow near the beach thrive as well at a height of 2,000 feet. The continual sunlight and the insignificant difference in temperature are undoubtedly the causes of this.

"The large granite blocks and broken stones, of which is formed the peculiar beach by which the fells are here almost always separated from the sea, are quite concealed by the most luxuriant moss and lichen vegetation. The grey covering, often six inches thick, is for the most part composed of lichens: Spharophoron fragile and Cladonia gracilis, Stereocaulon paschale, Cetrariaislandica-Iceland

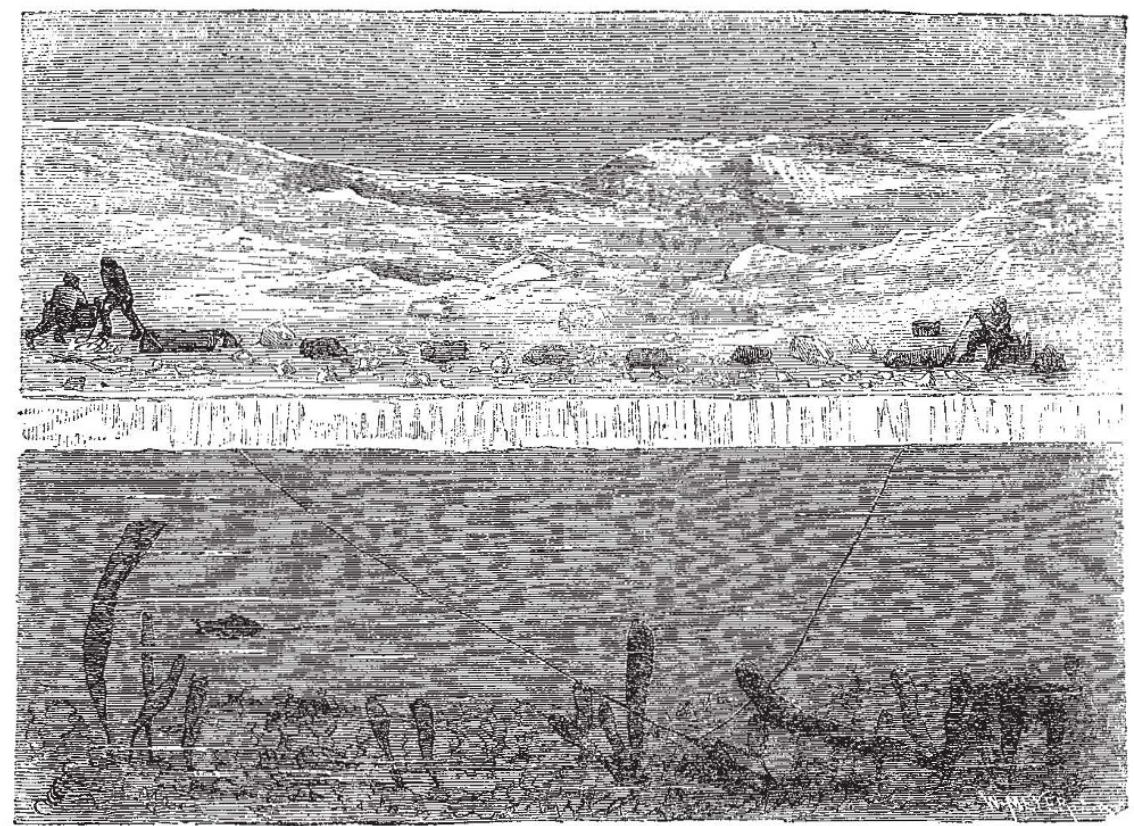

Dredging under the Ice in Winter.

moss--Bryopogon jubatum, Alectoria thulensis, Umbilicaria arctica, Solorina crocea and many others; and among mosses of Racomitrium lanuginosum, with stalks nine inches long, Encalypta rhaptocarpa, Gymnomitria and Brya, Polytrichum alpinum and Dicranum fuscescens, \&c. While the sloop lay in Magdalena Bay Cape Mitre was visited, a promontory which Scoresby ascended one of the few times he landed on Spitzbergen. When he had reached the summit, he was obliged to sit astride the ridge in order to keep his place. On July $3 \mathrm{I}$ the Magdalena again put to sea, and the same day anchored in Cross Bay. In this neighbourhood the first known fern on Spitzbergen was found-Cystopteris fragilis."

In the neighbourhood of King's Bay, was found a seam of coal, together with impressions of leaves and other parts of plants, showing that there was a period in the development of the globe when spreading forests, compose l, it would appear, chiefly of broad-leaved trees, resembling maples, everywhere covered the valleys and mountainslopes, where now, if they be not entirely filled with thick beds of ice, the Arctic willow, creeping inch high along the ground, is the only representative of plants of the nature of trees.

Thus sailing from one point to another, making boat and land excursions, dredging and collecting plants, animals, fossils, and minerals, and studying ice and other physical conditions, the members of the expedition carried on their work, returning only when the ice threatened to lock them in for the winter. This is a fair example of the methods and results of the various expeditions in which Nordenskjöld has been engaged.

In the third expedition to Spitzbergen, in which Nordenskjöld was engaged, that of 1864 , he himself was leader. The vessel was an old but strongly-built gunboat, the Axel Thordsen, of $26 \frac{1}{2}$ tons, part of the object of the expedition being to complete the preliminary survey to ascertain the possibility of measuring an arc of the meridian. On this occasion the expedition succeeded in landing on Bear Island, but on a subsequent expedition it was explored for five days. On the visit of 1864 Nordenskjöld inserted a water-mark at the Burgomaster Port, to register the rise of the land, which is going on in Spitzbergen as in other Arctic lands. After attempting 
Stor Fjord, the expedition made for Ice Fjord, which, at its east end, sends off three branches. A careful examination was made of several parts of the coast of this fjord, and in the neighbourhood of the North Fjord Nordenskjöld collected a large number of triassic fossils, among them large nautilus-like shells and fragments of bones, some of which were thought to have been four feet long, belonging to crocodile-like animals. While in Ice Fjord, the expedition met with Mr. Birkbeck's yacht Sultana, " a beautiful but fragile nutshell," having among others on board, Prof. Newton. Here also a water-mark was fixed. After leaving Ice Fjord, the Axel Thordsen succeeded in reaching Stans Foreland, a large island to the south-east of the main island, having on its south the Thousand Islands.

"Fortunately it appeared that the discouraging descriptions of the fogs prevailing here are properly applicable to the Thousand Islands, comparatively clear weather, on the contrary, being common in the inner part of the fjord. Here, as at many other places on Spitzbergen, may be found cloudless skies and sunshine, while an impenetrable fog lies at the mouth. The cause of this is to be sought for in the course of the marine currents. While an arm of the Gulf Stream, as the masses of drift-wood heaped up at South Cape and the Thousand Islands show, at least during a portion of the year, flows past the southern part of West Spitzbergen and Stans Foreland, it is the Arctic current entering from Helis Sound and Walter Thymen's Strait, which principally prevails in the interior of Stor Fjord. There is, therefore, no drift-wood to be met with on the shores of this fjord, on which account it is necessary on boat voyages to carry a supply of fuel. During boat voyages along the north coast of Spitzbergen one may, on the contrary, nearly always reckon on finding in the neighbourhood of the restingplace dry and excellent material even for a large log fire."

The west coast of Stor Fjord is occupied by enormous glaciers, which go down to the sea and are only interrupted by black, often conically-shaped mountain tops. On the east coast, on the contrary, between Whales' Point and Helis Sound, there is only a single considerable glacier, the coast being formed of a continuous rocky wall, which rises almost directly from the sea to a snowfree plateau of about 1,000 feet in height. At the foot of this wall there are here and there grassy slopes, which form the finest reindeer grounds on Spitzbergen. The west coast both of Stans Foreland and of Barents Land was examined as far north as the extremity of the fjord. In connection with this part of the expedition's work, some interesting remarks are made on the character of the Spitzbergen glaciers:-

"When icebergs are spoken of in the region of Spitzbergen, it ought to be remembered that what is meant is large blocks of ice which fall down from the perpendicular sea faces of the glaciers. Though these blocks are often exceedingly large, they cannot in any way be compared with the icebergs in the Greenland waters, which are said to reach a height of 1,000 feet. The glaciers on Greenland near the sea are indeed higher than on Spitzbergen, but this dissimilarity is not sufficiently great to explain the great difference in the dimensions of the glaciers at the two places. There is great probability in Prof. Edlund's hypothesis that the larger icebergs are formed by blocks of ice falling down from a glacier coming in contact in their lower parts with an over-cooled stratum of water which, as is well known, in contact with actual ice immediately assumes the solid form. For any such over-cooled stratum of water can, on account of the Gulf Stream, only exceptionally occur on the coasts of Spitzbergen, while the contrary is the case in the waters of Greenland, which are taken up almost exclusively by the Arctic current. The ice seeds which have fallen from the glaciers thus find only at Greenland a suitable soil for their further development, only there do they grow to enormous ice-masses, which are so often the cause of the navigator's astonishment and alarm."

(To be continued)

\section{HERING'S THEORY OF THE VISION OF LIGHT AND COLOURS}

A FEW years ago Herr Ewald Hering, Professor of -1 Physiology at Prague, communicated to the Imperial Academy of Sciences at Vienna a series of six papers propounding a new explanation of the physiology of vision, so far as concerns the perception of light and colour. The papers were subsequently collected and published in a separate form ${ }^{1}$ and have had a wide circulation. The author is well known by his researches on various "physiological subjects, and has long devoted attention specially to the phenomena of vision, many of his views having been discussed at much length in Helmholtz's "Handbook of Physiological Optics," published between 1856 , and I 866 .

The principles developed in the papers in question have attracted much attention on the Continent, and, it is believed, have been thought well of by many competent authorities. So far as I know, however, no account of them, beyond meagre notices of a few lines, has yet been made accessible to English readers. It is highly desirable, both for the reputation of the author and for the information of those of our countrymen who are interested in the subject, that this want should be supplied, and I propose now to offer to the readers of NATURE an abstract of Prof. Hering's theory, sufficiently explicit to enable its general nature to be understood, but at the same time not so full as to supersede reference to the work itself by those who desire to appreciate the reasoning more thoroughly.

The theory of the perception of light and colours at present best known and most generally adopted, is the one formed on the views of Thomas Young, and further elaborated by Helmboltz in his great optical work-hence called the Young-Helmholtz theory. That which Hering proposes to substitute for it may rather be considered as an extension and an improvement than an opposing theory, inasmuch as its chief aim is, by the introduction of additional elements, to account for phenomena which, according to the previous hypotheses, are left obscure, or receive insufficient explanations. This consideration will insure for the theory a more favourable reception than if its object were completely to overturn received ideas. It is not, however, intended here to offer any discussion of the theory; we have only to state what its general features are.

In the first place, it should be explained that the theory is developed chiefly in regard to the vision of black and white, and their mixture, gray. The subject of colour is introduced afterwards, following out the same principles.

The reasoning is founded for the most part on a class of visual phenomena of a subjective nature, such as the effect of contrasts, appearances after looking steadfastly at objects, and so on. These phenomena have long been considered important in regard to the theory of vision, and they are treated of by Helmholtz at much length. The author, however, contends that the endeavours made to explain them have been hitherto imperfect, inasmuch as it has been necessary to call in for this purpose the aid of psychological considerations, such as the effect of imagination and other causes of deception. As he expresses it, on every other page of a professed treatise on physiological optics, one finds the mental judgment invoked as a deus ex machinat to explain any sort of diff-

I "Zur Lehre vom Lichtsinne.". Sechs Mittheilungen an die kaiserl. A kademie der Wissenschaften in Wien. Von Ewald Hering, Professor der Physiologie in Prag. Zweiter Abdruck. Wien, 1878 . 